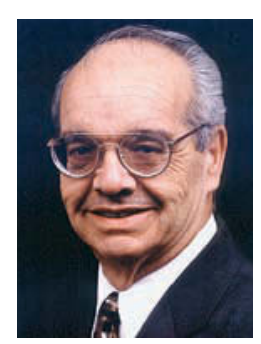

W. R. Gomes

Vice-President

Agriculture and

Natural Resources

\title{
ANR Looks to the Future
}

$\mathrm{W}^{\mathrm{h}}$ hen we began our last strategic planning review for the Division of Agriculture and Natural Resources (ANR) in 1997, California's economy was booming. The state was experiencing doubledigit revenue gains, largely fueled by the high-technology sector, and UC saw its base budget increasing after the lean years of the early 1990s.

The Division also shared in new revenues during the boom times, with ANR research augmented \$1.5 million in 1997-1998 and Cooperative Extension's (CE) budget increased \$3 million between 1998 and 2000. As we entered the new millennium, we were planning for expansion in our $\mathrm{CE}$ advisor and specialist ranks and modest, but incremental growth in our research.

This changed suddenly and dramatically in early 2002 on news that a sharp decline in tax revenues would leave California facing a $\$ 35$ billion budget shortfall. As a consequence, UC lost nearly $\$ 1$ billion in state funds over the next 24 months; ANR saw its research program cut \$19 million (20\%) and CE by $\$ 12.5$ million (25\%).

Since ANR state funds mainly pay for salaries and benefits, the cuts caused significant reductions in administrative, field support and academic positions. In all, nearly 350 campus and systemwide positions were lost through retirements, layoffs and attrition, or will not be filled. We eliminated or consolidated a number of statewide programs, allocated temporary funds to salaries and benefits to avoid further layoffs and made deep reductions in administrative budgets in Oakland.

When the potential impact of the state budget crisis became clear in late 2002, the deans, other ANR leaders and I began the process of re-evaluating the scope of programs for ANR. We were determined to get a clear picture of available resources, short- and long-term, evaluate and identify the strengths and limitations of the Division, and change how we do business.

Our goal was to think more strategically about ANR. What should we look like in the future? How should we invest our limited resources? Where could ANR make a difference? Early on we recognized the value of fully involving external stakeholders and the ANR community in both an advisory and consultative role during these deliberations.

In spring 2003, we commissioned three studies that looked at organizing $\mathrm{CE}$ for the future, potential cost-recovery programs to augment CE funding, and options for improving the ANR statewide organization. The recommendations and findings from these reports were posted online to make them accessible to as broad an audience as possible.

In January and February 2004, we held five listening sessions across the state to solicit input from stakeholders, partners and ANR employees. More than 500 people attended these public meetings and their input, insights and recommen- dations were invaluable. Several recurrent themes emerged.

Participants urged us to focus ANR programs and resources on high-priority issues; maintain county-based CE; improve coordination across campus, county and statewide programs; and increase opportunities for external stakeholder participation in ANR planning efforts.

I want to share our progress in focusing ANR programs and resources on high-priority issues. This recommendation was heard from our stakeholdeers at every listening session, and makes sense fiscally and programmatically given the budget cuts of the past 2 years. We realize we cannot continue to try to be all things to all people. We know that our options, over the short term, are somewhat limited without an infusion of new permanent state funding.

In the meantime, ANR's leadership will focus the Division's resources on programs where we can make the greatest difference. In September 2004, on the recommendation of the ANR Program Council, we adopted a set of priorities or core issues, which will be used in the short term for the allocation of discretionary ANR resources to fund competitive grant programs and other collaborative efforts. Over the long term, they are expected to influence hiring decisions for CE advisors and specialists and to further define ANR programs and priorities.

The Program Council identified and recommended 21 core issues they considered to be of the greatest relevance and importance to California's agricultural, natural and human resources sectors and appropriate to ANR's mission.

High-priority core issues are food safety, invasive species, pest management, sustainability and viability of agriculture, water quality and youth development.

Medium-priority core issues are air quality, biosecurity, human nutritional status, land use, obesity, organic production, soil quality, sustainable use of natural resources, waste management, water supply and allocation, and wildland fire.

Low-priority core issues are agricultural labor, community development, family and consumer well-being, and food security. The low-priority issues, while recognized as representing critical needs for California and important fields of endeavor for ANR, are areas where new investment of resources is not likely in the near future.

We are already using the core issues and priorities established by the Program Council as the basis for a new ANR competitive grants program announced on Sept. 15. The UCANR Core Issue \& Target Opportunity Grants Program will allocate approximately $\$ 800,000$ in discretionary funds for collaborative research projects, based on the six high-priority core issues and two of the medium-priority issues (obesity and sustainable use of natural resources). Proposals are due Nov. 15.

By focusing our limited resources according to these priorities, ANR will continue to deliver the high-quality research and extension programs that Californians need to remain competitive in global markets and maintain their quality of life.

For more information, go to http://groups.ucanr.org/directions/ 